\title{
Enhancing Social Integration and Work Performance: The Role of Expatriates' Significant Other
}

\author{
Marlin Abdul Malek ${ }^{1}$, Abd Rahim Jaguli ${ }^{1} \&$ Mohd Rizal Palil ${ }^{2}$ \\ ${ }^{1}$ School of International Studies, UUM COLGIS, Universiti Utara Malaysia, Malaysia \\ ${ }^{2}$ Faculty of Economics and Management, Universiti Kebangsaan Malaysia, Malaysia \\ Correspondence: Marlin Abdul Malek, School of International Studies, UUM COLGIS, Universiti Utara \\ Malaysia, 06010 Sintok, Kedah, Malaysia. Tel: 60-4-928-4093. E-mail: marissa@uum.edu.my
}

Received: June 12, 2013 Accepted: July 29, 2013 Online Published: September 29, 2013

doi:10.5539/ass.v9n13p215

URL: http://dx.doi.org/10.5539/ass.v9n13p215

\begin{abstract}
International assignments remain a crucial aspect of multinational corporations' global strategy, even with their high costs. While multinational corporations (MNCs) must consider the advantages and disadvantages of hiring local employees for specific roles, expatriates' roles are still significant. Culturally adjusting to the local environment has always been a problem for most expatriates and their accompanying family members. Failing to adjust culturally will lead to mediocre performance and under-utilising the wealth of host country-related information that only locals possess. Therefore, this research highlights the influential role that accompanying expatriate spouses could play in ensuring the smooth communication and cooperation between expatriates and their local subordinates and the local community. Path analyses of 134 expatriate and spouse related matched datasets show that spouses are more positively accepted by the host country nationals (HCNs) as opposed to expatriates. New relationships emerged from the path analyses which indicated the influential roles that spouses play in establishing better rapport with the locals. As such it is suggested that spouses are the 'missing link' that could foster better social integration and cross cultural communication and adjustment between expatriates and the host country nationals. Theoretical and managerial implications are subsequently discussed and future research suggestions are then put forth.
\end{abstract}

Keywords: expatriate, spouse, adjustment, social integration, performance, host country nationals

\section{Background of Study}

Despite the battle to minimize the costs involved in sending expatriates abroad, international assignments remain a crucial aspect of multinational corporations' global strategy. Common reasons expatriates give for prematurely terminating their international assignment include poor cross-cultural adjustment or adaptation (Takeuchi, Yun \& Tesluk, 2002), family-related problems, i.e. the inability of spouse and children to adapt to the host country's culture (Flynn, 1995; Takeuchi et al., 2002; Tung, 1987) and lack of ability to adapt to the various aspects of the host country (Pomeroy, 2006). Previous studies (Black, Gregersen \& Mendenhall, 1992; Takeuchi, 2010) have shown that the need to improve the ability to predict success of international assignments is vital because of the fact that many global assignments fail. These failures ranged from monetary expenses, negative company image, stalled career progression and psychological barrier to take up future assignments (Black, Gregersen \& Mendenhall, 1992; Hemmasi, Downes \& Varner, 2010). Takeuchi (2010) asserts that despite being extensively researched for the past few decades, most of the expatriate-related research has been predominantly 'expatriate-centric' and have neglected other expatriate stakeholders that include accompanying spouse, HCNs and the parent company or MNCs. Therefore, this research endeavors to increase the possibility of ensuring expatriation success by focusing on the influential role that the accompanying expatriate spouses or the expatriates' 'significant other' could play in creating a more harmonious and conducive environment to foster better social and work relationships between the expatriates and the host country nationals whilst in the host country. Consequently, a better support from the local staff and community would help to manage and minimize the feelings of anxiety and uncertainty that comes from being relocated to a new cultural environment and would further contribute to better facilitate intercultural communication and cross-cultural adjustment.

Asia in particular represents a challenging posting for many foreign managers. Wide differences between the cultural, perspectives and mannerisms may pose awkward and baffling situations for those who are relocating to 
this part of the world (Neupert, Baughn \& Dao, 2005). Many managers who have succeeded in their domestic operations may often find that the mental maps that they have relied on for so many years do not necessarily apply when they relocate (Black \& Gregersen, 2000). Malaysia is one example where one might expect to find all these wide differences.

This paper is organized as follows. We first present a review of literatures related to the theoretical stance underpinning the concept relating to social integration, support, expatriate adjustment and performance. Next, we develop hypotheses based on the reviewed literature. Further, we describe the method, study sample and measures before proceeding with the reporting of results of the statistical tests. Finally, we conclude with the discussion on findings and their implications for both the academic research and practice suggestions for future research.

\section{Literature Review}

\subsection{Anxiety Uncertainty Management (AUM) Theory}

Both novice and seasoned expatriates would tend to feel anxious of any new posting simply for the fact that no two cultures are alike. Black (1988) contended that in order to feel comfortable with the new culture, expatriates need to reduce their uncertainties and make some changes to their behaviors. Gudykunst (1988) concurred that anxiety and uncertainty are critical factors in understanding effective communication and intercultural adjustment. The anxiety/uncertainty management (AUM) theory by Gudykunst (see 1988, 2005; Gudykunst \& Hammer, 1988) was first coined to improve the quality of communication and adjusting to living in new cultures. The AUM Theory, calls for better management of anxiety and uncertainty in order for newcomers to adjust better to the new environment. Based on the uncertainty reduction theory (URT) by Berger and Calabrese (1975), with AUM Theory, ideally culturally adjusted expatriates would most likely perform their tasks effectively (Black, 1988; Black \& Mendenhall, 1990) and are able to achieve work and non-work satisfaction (e.g. Shaffer \& Harrison, 1998; Takeuchi et al., 2002), organizational commitment (Shay \& Baack, 2006; Takeuchi, Wang, Marinova \& Yao, 2009), minimize withdrawal cognitions (e.g. Shaffer \& Harrison, 1998; Wang \& Takeuchi, 2007) and performance (Caligiuri, 1997; Kraimer et al., 2001; Kraimer \& Wayne, 2004; Shay \& Baack, 2006).

Previous scholars found support which proves that expatriates go through the processes of learning and exhibiting new behaviors in order to 'fit in' with the host cultures (see Berry, 1997; Black \& Mendenhall, 1990; Black, Mendenhall \& Oddou, 1991). Expatriates generally arrive at a new assignment with a defined role, a set of responsibilities and an established organizational support system. In contrast, spouses usually have a harder time adjusting. Isolated from family and friends and living in a foreign environment with different legal, political, and social (cultural \& language) systems, the adjustment process for spouses may be especially frustrating and stressful (Albright, Chu \& Austin, 1993). Scholars have also proved that expatriates do rely on family members, organizations and $\mathrm{HCNs}$ to provide them with the desired support especially in the initial stage of relocating to the host country (Kupka \& Cathro, 2007; Toh \& DeNisi, 2005).

In 1990, Black and Mendenhall used social learning theory (Bandura, 1977) to explain the theoretical underpinnings for how pre-departure cross-cultural training could have a positive impact on the interactions expatriates would have with host nationals. Black and Mendenhall (1990, p. 120) suggest that 'cross cultural training enables the individual to learn both content and skills that will facilitate effective cross-cultural interaction by reducing misunderstandings and inappropriate behaviors.' Although pre-departure cross-cultural skills training are important for cross-cultural adjustment, many organizations simply do not provide it for their expatriates (Black \& Mendenhall, 1990), and in turn, the bulk of learning actually occurs in the host country. As such, in this research, emphasis is on how expatriates and their family members strive to display appropriate behaviors that can be observed and learnt from those in their vicinity as a way for them to be accepted into the in-groups thus facilitating their adjustment and work related performance. This research will only stress on why the acceptance of host country nationals towards accompanying expatriate spouses in more influential in addressing and fostering better relationships between the expatriates and the HCNs.

\subsection{Cultural Intelligence}

Gudykunst (2005) claims that uncertainty is a cognitive phenomenon where it affects the way we think about strangers. Schlenker and Leary (1982) contend that social anxiety happens because we want others to have a favorable impression of us but we doubt our ability to deliver that. As such, to transcend these cultural boundaries, expatriates and their family members should have the ability to appropriately address and react to intercultural situations and cultural intelligence (CQ) may be the skill that can help to improve the capability for successful adaptation (Peterson, 2004; Thomas \& Inkson, 2004). It is proposed that by being culturally intelligent, expatriates and their accompanying family members would therefore manage their anxiety and 
uncertainty associated with relocating to a different cultural background thus putting in more effort for work related task accomplishment and/or socially integrating into the new environment. As such, the researchers feel that CQ would tremendously facilitate the expatriate and their family members' quest to manage their anxiety and uncertainty stemming from intercultural encounters with strangers in the host country and consequently achieve better adjustment and increased performance while working and residing in the host country.

\subsection{Spouse-Related HCN Support}

As expatriates would be more immersed with their assigned tasks, spouses are generally more directly involved with the local environment on a daily basis in order for them to ensure the expatriate family can continue with their normal daily activities with the least of disruption. Isolated from family and friends and living in a foreign environment with different legal, political, and social (cultural \& language) systems, the adjustment process for spouses may be especially frustrating and stressful (Albright, Chu \& Austin, 1993). HCNs can also be considered as a group that are most conversant with the host country's cultural aspects and as such would be the most suitable group for the spouses to get information from regarding the various aspects that they might encounter in the host country, especially in the initial stages of relocation. Host country social support is a form of informational support; support for providing information to make life easier in the host country and emotional support, non-tangible help that could make a difference to a newly relocated family. Shaffer and Harrison (2001) claim that interaction with host-country nationals builds an appreciation of and sensitivity to cultural differences; naturally it seems likely that deeper relationships with host country nationals would also facilitate adjustment. As Furnham and Bochner (1986) noted, relationships with host country nationals help to bridge the gap between the two cultures. Such relationships create a climate of mutual respect and understanding, thus increasing the likelihood of adjustment to the international assignment (Bell \& Harrison, 1996). Hence, based on the above findings, the following hypothesis is developed to investigate the impact of host country social support on spouse adjustment.

Hypothesis 1 - Spouse host country national social support (SPHCS) will be positively related to the spouse adjustment. (SPADJ)

\subsection{Cultural Intelligence of Expatriate's Spouse}

Being culturally aware and exhibiting culturally sensitive behaviours could make the HCNs more welcoming towards the newly relocated expatriate families. This is especially helpful when the spouses need to depend on HCNs for support and information regarding cross-cultural situations as they are more directly involved with the local environment. In line with Tajfel and Turner's social identity theory $(1982,1986)$, spouses do want to be included in the in-groups in order to increase their self-worth and one's identity concept. Thus, factors like knowing the local language and cultural values could increase their chances of becoming accepted by the locals. Additionally, being culturally intelligent could enhance individual interactions across cultures (Earley \& Ang, 2003) thus allowing for opportunities that could serve one's goals (Brislin et al., 2006) i.e. the acceptance by the in-groups of HCNs. With the above findings and the scarcity of empirical evidence relating to cultural intelligence, the following hypothesis is developed to determine the influence of CQ on spouse adjustment.

Hypothesis 2 - Spouse cultural intelligence (SPCQ) will be positively related to the spouse adjustment (SPADJ)

\subsection{Adjustment on Performance}

In order to ensure each expatriate will perform as expected, organizations should be able to predict or identify what are the relevant antecedents or stressors that could maximize expatriates' performance. Campbell (1990) defines job performance as a set of behaviors that are relevant for the goals of the organization and the effectiveness of the outcomes that stem from these behaviors. Translating the latter definition to the realm of expatriates, a definition for expatriate effectiveness is the extent to which the expatriate's job performance reflects behaviors that are relevant to the organization's goals. Research on expatriates has found mental well-being to be positively correlated with all three dimensions of expatriate adjustment (Nicholson \& Imaizumi, 1993; Selmer, 1998) suggesting that individuals who are poorly adjusted may be experiencing psychological stress. Borman and Motowidlo (1997) divide the performance domain into a contextual and a task domain. They define contextual performance as activities that are directed at maintaining the interpersonal and psychological environment that needs to exist to allow the technical core to operate and argue that contextual performance is important because it shapes the organizational, social, and psychological context that serves as a critical catalyst for task activities and processes (Borman \& Motowidlo, 1997). Contextual performance can sometime be viewed as relationship-based performance (Podsakoff et al., 2000). Task performance on the other hand is defined as the effectiveness with which job incumbents perform activities that contribute to the organization's technical core either directly by implementing a part of its technological process, or indirectly by providing it with needed materials or services (Borman \& Motowidlo, 1997). Tucker, Bonial and Lahti (2004) note that the relationship 
between cross-cultural adjustment and job performance is complex and not very well understood.

Research by Kraimer et al. (2001) found that there is a positive relationship between expatriate adjustments with performance however they find no existing data on the relationship between spousal adjustment and expatriate performance. Nevertheless, Shin, Morgeson and Campion (2007) found explicit support in the expatriate literature for the fundamental assumption that expatriates need to adjust to new cultural environments by adapting their behavior to fit the host country's cultural norms and values in order for them to be successful at work. Similar supports come from meta-analyses that show that expatriate adjustment is an important predictor of performance (Bhaskar-Shrinivas et al., 2005; Hechanova, Beehr \& Christiansen, 2003). As is the case with many supposed relationships between variables in the expatriate management domain, to date there is no data to back the claim that spousal adjustment is critical to expatriate job performance, perhaps it should be gathered more conscientiously and deserves more thorough attention to form possible conclusion (Kraimer et al., 2001). However, as the majority of expatriates are in the host countries with their family members, the family members' roles in supporting expatriate adjustment and performance could not be relegated aside. Punnett (1997) found that with effective management from the organizations, spouses can contribute to expatriate adjustment and subsequent performance. Based on the above analysis, hypotheses three is developed.

\section{Hypothesis 3 - Spouse adjustment (SPADJ) will be positively related to expatriate performance (PERFORM)}

\section{Methodology}

\subsection{Study Procedures and Sample Characteristics}

The main research population consists of expatriates and their spouses who are working in MNCs and residing in Malaysia. Their contact details were gathered from the databases in expatriate associations and chambers of commerce as the full list of expatriates in Malaysia were confidential. Postal and web surveys were used to gather response from the respondents. Dillman (2007) suggested that web surveys can be used simultaneously with postal surveys to maximize response rates and counter the drawback of the other mode. Survey packs that consist of an explanatory letter, an expatriate questionnaire, a spouse questionnaire and stamped returned envelopes were sent to 704 expatriates. In order to capture a more holistic picture of the adjustment process and the social support required and received by the expatriates and their family members and the linkage with the expatriate's performance, this research includes responses from the expatriate's spouse or partners in order to have a more comprehensive understanding from the lens of those that normally surrounds the expatriates. Overall, 134 expatriate responses were received from both the postal and on-line surveys (response rate 19.1\%).

For this study, a number of variables were used to control for the effect of certain factors on the tests of relationships between variables. For example, time in the host country, having accompanying family members during assignments, fluency of local language and having previous experience act as control variables so they remain constant while testing for the relationships between variables carried out so that the results would be more reflective of the actual conditions. The adoption of these variables is in line with previous expatriate related research (Black \& Mendenhall, 1990; Caligiuri, 2000; Mendenhall \& Oddou, 1985). None of the control variables had any significant impact on any of the adjustment variables. In addition, prior to distribution of surveys, a pilot study sample consisting of Human Resource Management experts, expatriates and government officials were undertake to pre-test the instrument $(\mathrm{n}=20)$. Pilot studies also allow for the testing of face validity when the items appear to reflect the construct as defined conceptually (Schwab, 2005). Apart from suggestions to simplify certain statements and be consistent with certain terms, the respondents from the pilot study were satisfied with the survey items.

\subsection{Instruments and Measures}

Survey items for HCNs' social support (HCNS) to spouse/family members are adopted from earlier scales by Kupka and Cathro (2007) and Wang (2001). The expatriate spouses/partners were asked to respond with regards to the support given by their local community in their current overseas residence. Sample item for this measure is 'my friends/acquaintances in the host country gave me information about the host country customs'. All scales related to the $\mathrm{HCN}$ support constructs were on 7 point Likert scale where $1=$ strongly disagree and $7=$ strongly agree. Cultural intelligence (CQ) was measured using a scale put forth by Ang et al. (2007) and Van Dyne (2005). The CQ scale, consisted of 20 items were on a 7-point Likert scale ranging from $1=$ strongly disagree to $7=$ strongly agree. Some sample items used in this scale include 'I am conscious of cultural knowledge I use when interacting and I am confident that I can socialize with locals of other cultures'.

Family members' adjustment was operationalized with an extended version of a previously developed instrument by Black and Stephens (1989) and improved by Shaffer and Harrison (2001). The work adjustment items from the original scale by Black and Stephens (1989) were omitted to suit the nature of the expatriate family members. 
Expatriate performance was measured using a combination of scales put forth by Caligiuri (1997), Kraimer et al. (2001) and Kraimer and Wayne (2004). The performance, segregated into task and contextual performance are on a 7-point Likert scale ranging from $1=$ very poor to $7=$ outstanding. The respondents were asked to rate their performance on how they are doing in their current roles. It was originally decided to use the co-workers' ratings for expatriate performance as a way to counter the disadvantage of self-reporting, however, further analysis showed that there was no significant correlations between the co-worker expatriate performance ratings and the various adjustment facets. Thus the co-worker ratings were dropped and the self-performance ratings were used instead.

Correlations were used to initially test the hypotheses. Scale reliability was tested using internal consistencies measures (Cronbach coefficients). Exploratory factor analysis (EFA) was used initially to establish the principal constructs, and then confirmatory factor analysis (CFA) was drawn upon to establish convergent and discriminant validity. Since the number of respondents is less than $150(n=134)$, which is the minimum number required to run a full Structural Equation Model (Anderson \& Gerbing, 1988), we have analyzed the theoretical model using path analysis, which is an alternative for looking at relationship of all variables simultaneously (Loehlin, 2004). All constructs subsequently used in the path analysis had valid psychometric properties that help to mitigate the assumptions underlying path analysis. Data analysis was performed using AMOS 16.0 from data files in SPSS 16.0 (Arbuckle, 2007).

\section{Results}

From the 134 matched pairs data, the majority of the expatriates were working for a MNC (98.6\%) while the rest were attached to either a semi-government agency or a non-for-profit organization. Almost $60 \%$ were in manufacturing, while $15 \%$ were from the oil and gas sector and the remaining were in information technology, hospitality and services industry. $76.1 \%$ were male and nearly fifty percent $(47.8 \%)$ were in their forties. $41.8 \%$ of the expatriates were from one of the European countries with $18.7 \%$ from the United Kingdom. $72.4 \%$ of the expatriates were non-Asians. $75.4 \%$ of the expatriates have been in the host country for less than 18 months. More than half (56\%) were first timers while $44 \%$ had at least two other previous assignments under their belts. All of the expatriates were in the host country $(\mathrm{HC})$ with at least their spouse or partner and $88.8 \%$ had their spouse and children or other dependent accompanying them. $62.7 \%$ were partly fluent in the $\mathrm{HC}$ native language. For the spouse, while $30.6 \%$ were working part-time in the HC, almost thirty percent $(29.9 \%)$ were involved in charity work and $37.3 \%$ had some form of employment; either working from home or were on unpaid leave. Table 1 summarizes the demographic details of the respondents.

Table 1. Demographic details ( $\mathrm{N}=134)$

\begin{tabular}{llll}
\hline Variables & (in \%) & Variables & (in \%) \\
\hline Male & 76.1 & Was their first assignment & 56.0 \\
Female & 23.9 & $\underline{\text { Average contract }}$ & \\
Between 40-49 years & 47.8 & 2-3 years contract & 68.7 \\
Between 30-39 years & 33.6 & With spouse/dependents & \\
Married & 99.2 & With at least spouse & 11.2 \\
Headquarters origin & & With spouse/dependents & 88.8 \\
UK (HQ) & 26.9 & Local language knowledge & \\
USA (HQ) & 16.4 & Partly fluent & $62.7,(\mathbf{6 2 . 7 )}$ \\
Expatriate origin: & & Type of industry & \\
UK & $18.7,(\mathbf{2 2 . 4})$ & Manufacturing & 18.7 \\
USA & $12.7,(\mathbf{8 . 2})$ & IT & 14.9 \\
India & 9.0 & Education & 11.2 \\
Singapore & $\mathbf{( 7 . 5 )}$ & Level in organisation & 65.7 \\
Average tenure: & & Top & 25.4 \\
7 yrs & 64.9 & Middle & 85.1 \\
Has been in the HC for: & & In country with at least 1 child & \\
6-12 months & $38.8,(\mathbf{3 8 . 8})$ & & 51.1 (49.3) \\
13-18 months & $36.6,(\mathbf{3 2 . 1})$ & Willingness to go for future assignments?
\end{tabular}

*Responses from spouse are in parentheses and in bold. 
Basic statistical analyses were carried out to test the correlations between each variable. Table 2 gives a summary of these figures.

Table 2. Descriptive statistics and correlations $(\mathrm{N}=134)$

\begin{tabular}{lllllllll}
\hline \multicolumn{1}{c}{ Scales } & Mean & SD & 1 & 2 & 3 & 4 & 5 & 6 \\
\hline 1.Spouse HC Support & 5.23 & 1.16 & $(.77)$ & & & & & \\
2. Spouse CQ & 5.26 & .73 & $.45^{* *}$ & $(.75)$ & & & & \\
3. SP General Adjust. & 5.00 & 1.15 & $.39^{* *}$ & $.38^{* *}$ & $(.77)$ & & & \\
4. SP Interaction Adjust. & 4.23 & 1.20 & $.34^{* *}$ & $.38^{* *}$ & $.53^{* *}$ & $(.75)$ & & \\
5. EXP Task Perform. & 6.17 & .53 & .05 & .03 & $.18^{*}$ & .03 & $(.79)$ & \\
6. EXP Context. Perform. & 5.48 & .74 & $.18^{*}$ & .08 & .05 & $.20^{*}$ & $.18^{*}$ & $(.86)$ \\
\hline
\end{tabular}

Notes: Reliability estimates are in parentheses, ${ }^{* *} \mathrm{p}<.01,{ }^{*} \mathrm{p}<.05$. Expat. $=$ Expatriate, $\mathrm{HC}=$ Host Country.

This research utilizes two main analyses; correlations and path analyses. The hypothesized relationships were developed from the available literature on the basis that there are three predictors of spouse adjustment and expatriate performance. Following correlations, a spouse adjustment path model was analyzed to test all hypothesized relationships simultaneously. The results of these analyses are reported in the ensuing sections. Path analysis, using AMOS 16.0, will allow the researcher to see the fit of the model as a whole and to determine whether there are any direct and indirect effects. Path analysis allows a simultaneous test of a system of theoretical relationships involving multiple dependent variables (Loehlin, 2004; Singh \& Wilkes, 1996). The model is then re-tested using theory-trimming technique through the removal of non-significant hypothesized relationships suggested by James, Mulaik and Brett (1982) and adopted by Mavondo and Rodrigo (2001).

\subsection{Path Analysis for Spouse Adjustment Model}

The spouse adjustment path model is to determine spouse specific subscales with spouse adjustment and expatriate performance. The original hypothesized model (Figure 1) is tested for the purpose of examining the hypothesized relationships in this study.

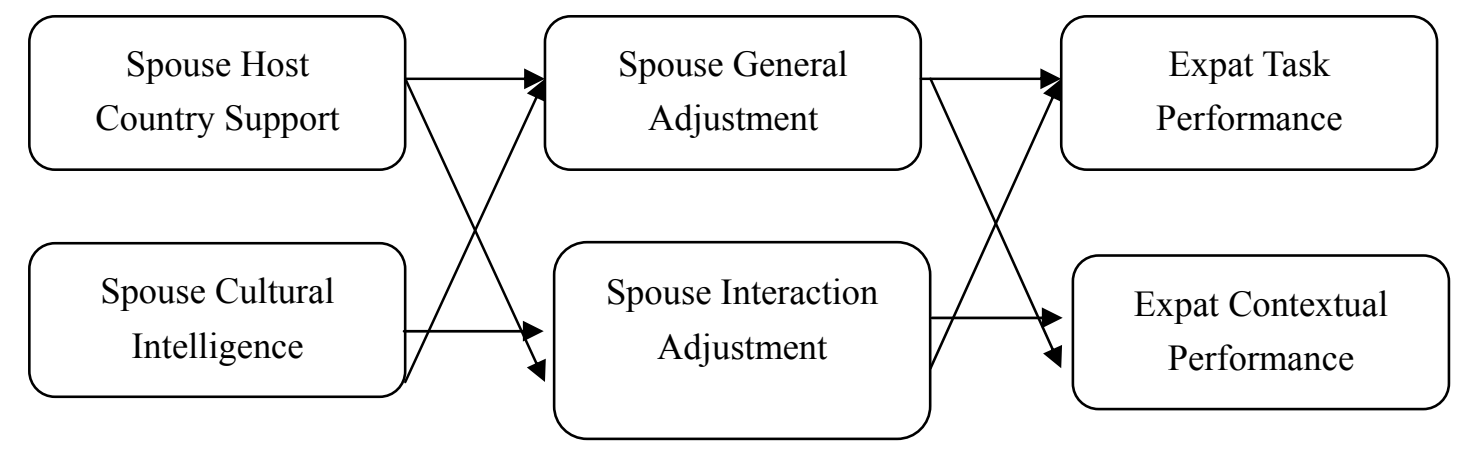

Figure 1. Spouse adjustment path model $(\mathrm{N}=134)$

This model produced a significant $\mathrm{X}^{2}$ and moderate goodness-of-fit indices. Using theory-trimming techniques, the model was then re-tested in order to get a better fit through the removal of non-significant hypothesized relationships. Table 3 provides the goodness-of-fit indices for both the original and final spouse adjustment path models. 
Table 3. Goodness-of-fit indices for the original and final spouse adjustment path models $(\mathrm{N}=134)$

\begin{tabular}{llll}
\hline Goodness-of-fit test & Original model estimates & Final model estimate & Interpretation (Final model) \\
\hline Model fit & & & \\
$\mathrm{X}^{2}$ value & $56.91(d f=14, \mathrm{p}=.000)$ & $11.88(d f=11, \mathrm{p}=.373)$ & \\
CFI & .89 & .99 & $\begin{array}{l}\text { The final model indicates a very } \\
\text { good fit with some indices very } \\
\text { close to } 1 . \text { The X }{ }^{2} \text { value is highly } \\
\text { significant. }\end{array}$ \\
$\begin{array}{l}\text { Goodness-of-fit } \\
\text { (GFI) }\end{array}$ & .92 & .98 & $\begin{array}{l}\text { The RMSEA and SRMR are } \\
\text { almost zero, indicating a very }\end{array}$ \\
Adjusted GFI & .70 & .94 & good fit. \\
Normed fit index & .87 & .91 & \\
(NFI) & & .025 & \\
RMSEA & .152 & .052 & \\
Standardised RMR & .073 & & \\
\hline
\end{tabular}

The final spouse adjustment path model is illustrated in Figure 3, where the figures on the model are standardized regression coefficients and are all significant at least $95 \%$ level unless indicated otherwise. The results of the final model are summarized in Table 4, and a summary of the hypotheses supported and not supported is provided in Table 5 .

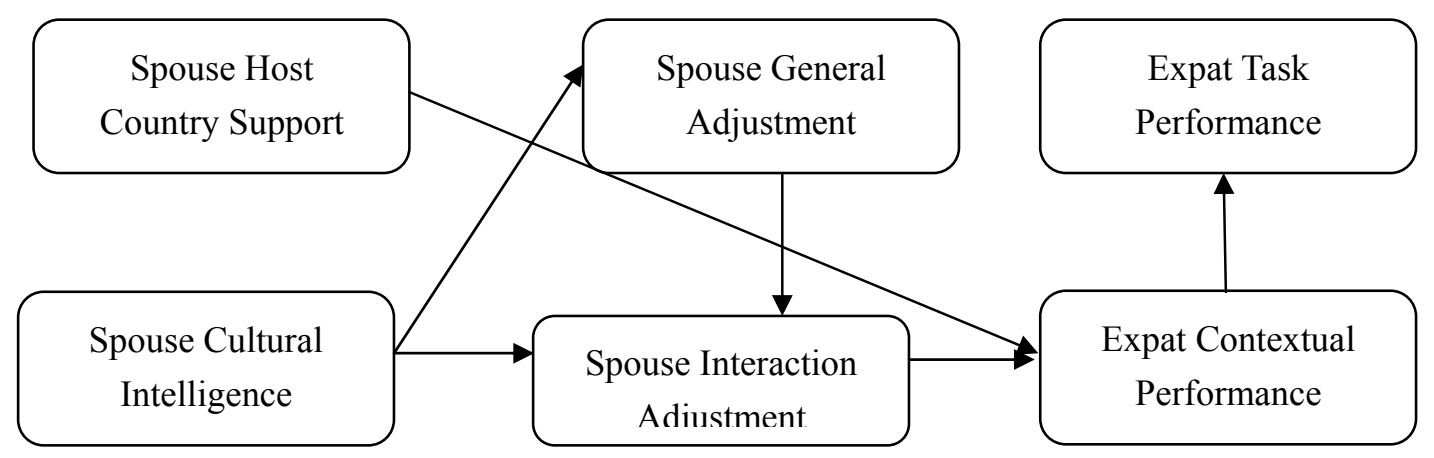

Figure 2. Spouse adjustment final path model $(\mathrm{N}=134)$

The results suggest mixed findings of predictors of spouse adjustment and expatriate performance. Only spouse cultural intelligence (Spouse CQ) is significant in assisting both general and interaction adjustment. This is to show that being aware of the cultural differences in the host country helps the spouse keep an open mind and be more receptive in any culturally challenging situations. However, spouse host country support (Spouse HC Support) is not a predictor of spouse general and interaction adjustments. This is a rather surprising because it has proven significant in previous research on expatriate adjustment model (Malek \& Budhwar, 2011). One possible explanation for this revelation is that the spouse might be getting support from other expatriate families that share some common interests as there are quite a number of expatriate related associations such as Association of British Women in Malaysia, International Women's Association of Kuala Lumpur or American Association of Malaysia where the spouse could befriend like-minded people. Another possible explanation is that with the advancement of technology, the spouse could use personal electronic communication like using Skype, Yahoo Messenger and chatting through Facebook to still be in contact with their loved ones back in their home countries. The results of the final spouse adjustment model and the effects of the hypothesized relationships are detailed in Table 4. 
Table 4. Direct, indirect and total effects for spouse adjustment path model

\begin{tabular}{|c|c|c|c|c|c|c|c|c|}
\hline & SGAJ & SGAJ & SIAJ & SIAJ & ECP & ECP & ETP & ETP \\
\hline Construct & Direct & Indirect & Direct & Indirect & Direct & Indirect & Direct & Indirect \\
\hline Spouse CQ & .425 & -ne- & .246 & .182 & -ne- & .056 & -ne- & .010 \\
\hline SP HC Supp & -ne- & -ne- & -ne- & -ne- & .213 & -ne- & -ne- & .040 \\
\hline SGAJ & -ne- & -ne- & .428 & -ne- & -ne- & .056 & -ne- & .010 \\
\hline SIAJ & -ne- & -ne- & -ne- & -ne- & .225 & -ne- & -ne- & .023 \\
\hline ECP & -ne- & -ne- & -ne- & -ne- & -ne- & -ne- & .175 & -ne- \\
\hline
\end{tabular}

Note: $* *_{-}$ne- $=$no effect

Although path analysis allows for the disclosure of indirect effects, for the spouse adjustment model, all the indirect effects are not significant and negligible with the exception of spouse cultural intelligence (Spouse CQ) with interaction adjustment (SIAJ). There is a significant direct effect between Spouse CQ with SIAJ. These additional insights would not be picked up in multiple regressions. Table 5 summarizes the hypothesized relationships for the spouse model.

Table 5. Results of the hypotheses based on the spouse adjustment path model $(\mathrm{N}=134)$

\begin{tabular}{lll}
\hline Hypothesis & Path Coefficients & Conclusion \\
\hline H1a - Spouse HC Support $\rightarrow$ Spouse General adjustment & Not significant & Not supported \\
H1b - Spouse HC Support $\rightarrow$ Spouse Interaction adjustment & Not significant & Not supported \\
H2a - Spouse Cultural Intelligence $\rightarrow$ Spouse General adjustment & $.43^{* *}$ & Supported \\
H2b - Spouse Cultural Intelligence $\rightarrow$ Spouse Interaction adjustment & $.25^{* *}$ & Supported \\
H3a - Spouse General adjustment $\rightarrow$ Expatriate Task performance & Not significant & Not supported \\
H3b - Spouse Interaction adjustment $\rightarrow$ Expatriate Task performance & Not significant & Not supported \\
H3c - Spouse General adjustment $\rightarrow$ Expatriate Contextual performance & Not significant & Not supported \\
H3d - Spouse Interaction adjustment $\rightarrow$ Expatriate Contextual performance & $.23 * *$ & Supported \\
New findings & & \\
General adjustment $\rightarrow$ Interaction adjustment & $.43 * * *$ & \\
Informational support $\rightarrow$ Contextual performzance & $.18 *$ & $.23 * *$ \\
On-site support $\rightarrow$ Contextual performance & & $\begin{array}{l}\text { More details } \\
\text { provided in }\end{array}$ \\
Contextual performance $\rightarrow$ Task performance & $.18 *$ & $\begin{array}{l}\text { ise discussion } \\
\text { chapter. }\end{array}$ \\
\hline
\end{tabular}

Note: ${ }^{*} \mathrm{p}<0.05,{ }^{* *} \mathrm{p}<.01,{ }^{* * *} \mathrm{p}<0.001$

Key: $\rightarrow=$ has a positive influence on

The path analysis shows that the predictors hypothesized for the spouse adjustment and expatriate performance are not significant in explaining both outcomes. With the exception of spouse cultural intelligence with both adjustments (EGAJ \& EIAJ) and interaction adjustment (EIAJ) with expatriate contextual performance (ECP), the predictors are not positively related to either the adjustment or performance variables. However, through the suggestion of modification indices, new relationship can be seen from spouse host country support with expatriate contextual performance (ECP). Echoing the finding from the research on expatriate adjustment that emphasis on social integration element (Malek \& Budhwar, 2011) both supports from organizations and host country nationals to spouses can be positively related to how expatriate fulfill their interpersonal roles in work and non-work setting. Consequently, the spouse adjustment model proves that spouses do influence how expatriates perform at work. 


\section{Discussions}

Tajfel (1982) highlighted that spouses could not adjust well to the new environment due to the loss of self-identity. They often struggle to find something in common with the locals thus they were left feeling isolated from the masses. Therefore, based on social identity theory, previous scholars found that it is important that spouses feel that they are part of the community (Tajfel, 1982; Tajfel \& Turner, 1985). The spouse adjustment path model highlights the influential role that spouses play in order to enhance expatriates' contextual and task performance through better cultural intelligent skills and support from the host country nationals. The results from the path analysis pertaining to the support from the HCNs showed positive relationships between the spouse social support from the HCNs and the spouse adjustment. This emphasized that support from those around the expatriate family does play a significant role in helping them adjust better to the new surroundings. The results supported previous findings from Black and Gregersen (1991) and Shaffer and Harrison (2001). The task to fit into the new environment becomes more daunting when you do not speak the local language. Mendenhall and Oddou (1985) concluded that local language knowledge could greatly facilitate interpersonal communication and relationship building.

In this study, more than half of the respondents said that they have no knowledge of the local language which is the Bahasa Malaysia. Although English is widely spoken, most signage are in Bahasa Malaysia. Thus without help from the locals, getting around to manage routine chores can be a hassle. Additionally, without the support and help from the HCNs, it is quite impossible for the newly relocated expatriate family to have any knowledge of this (Abdullah, 1992).

Unlike the informal relationships that are frowned upon between the authority figure or the expatriate with his/her subordinates, the HCNs are more receptive in developing friendships with the expatriate family members due to there is no authority involved and the expatriate's spouse and family are merely housewives or househusbands (Abdullah, 1996). Foreigners, especially western people, are generally being accorded higher status in Malaysia due to the HCNs being in awed of or 'curious' of those that are different. Malaysians are generally friendly and will go out of their way to help a person in need, especially when they see the expatriate spouse and family members take the time to learn the local language and are sensitive to the differences in culture (Malaysian Industrial Development Authority Report, 2009). This is reflective of the collectivist culture and on the religious teachings of Islam where a person is responsible for his/her immediate neighbors' safety and happiness (Schermerhorn \& Bond, 1997). According to the Global Leadership and Organizational Behavior Effectiveness (GLOBE) study, Malaysians score high on the humane orientation dimension, whereby the collective group encourages and rewards individuals for being altruistic, generous, caring and kind to others (Javidan \& House, 2002; Lim, 2001). Therefore, a newly relocated expatriate family will be accorded some form of help and support when they first set foot in the neighborhood and the neighbors will go out of their way to make the newcomers feel more at home in the new surroundings. However, this caring attitude can contribute to the invasion of privacy and can escalate into something of a nuisance to those westerners who value their personal space (Abdullah, 1992). However, the best way to adjust better to the local surroundings is to emulate behaviors of the locals. This supports the social learning theory (Bandura, 1977) where a person gains new insights from observing the behaviors of those around them and tries to emulate these behaviors wherever and whenever possible. This may sound trivial but introduction from locals would help tremendously in opening more doors (Abdullah, 1996). Therefore, by being part of a local group, expatriate spouses would be able to adjust faster and better to the new surroundings, freeing more time for them to support their spouses without having to fret on basic things. This could ultimately mean a change from basic living to comfortable living. This is in line with the findings from Lim (2001) where the combination of high humane orientation and family/group collectivism suggests potential privileges for in-group members. The inclusion of the spouse into the society's in-group will help to contribute to increase the spouse's social identification to the immediate society thus making them feel less isolated from the masses.

Stemming from social identity theory (Tajfel, 1982; Tajfel \& Turner, 1985), spouses would feel that they have more in common with the HCNs in terms of interests and abilities that they could offer to the HCNs thus increasing their feelings of self-worthiness. Additionally, the expatriate spouse in return could gain more support from the local community if they are viewed to have something that they could contribute to the society. This contribution to general society is reflected upon the social capital theory (Lin, Cook \& Burt, 2001) where an inclusion of an outsider into an inner circle can be hastened when the outsider is deemed to have something of importance that they could contribute in return for getting the benefits only an insider could gain.

The path analysis results show there are no direct effects between spouse host country support with any facet of spouse adjustment. However, spouse host country support was found to be directly linked to expatriate 
contextual performance. This is an interesting finding because a spouse could be the connecting element or the 'missing link' that could help expatriates to socially integrate with the HCNs both in the work and non-work setting. Earlier findings have shown that host country social support was not significant to expatriate adjustment and performance possibly due to the power distance element that is inherent to the locals (Malek \& Budhwar, 2011). Expatriates who normally occupy top management positions, due to the differences in status, do not have informal relationships with their subordinates. Spouses, on the other hand, are seen as less authoritative figures and treated with more warmth and mostly are more welcomed in the society. Thus it was easier for spouses to gain access to the wealth of information that the HCNs possess and in turn use this information to help the expatriates making them more accessible to the local counterparts. This is especially helpful in making the expatriates more sensitive to cross-cultural nuances and ensuring leader-follower interactions are better understood (Schermerhorn \& Bond, 1997).

In summary, the issues discussed in length in the previous paragraphs testify to the influence of the local community on the expatriating families' well-being. Thus, expatriate spouses' influential roles in establishing a more neutral ground, without the influence of authority and depth of information disclosure between the expatriates and the local subordinates and community could be the 'missing link' that can contribute to a better social and working relationships between the two parties. The conservative old view that only see spouses as somebody that only accompany expatriates on assignments can be tossed inside and replaced with viewing spouses as the 'liaison' or the 'conciliator' in expatriate and host country nationals' relationships.

Referring to the path analysis results, Cultural Intelligence was more significant to the spouse adjustment because there will be more opportunity for expatriate spouses to encounter situations where their cultural knowledge will be tested due to them having to meet more HCNs in performing their daily activities. The expatriates, although working alongside HCNs in the workplace, their behaviors will somehow be dictated by the existing corporate culture due to the MNCs having policies and regulations that are quite similar with the headquarters and other subsidiaries. What would be different is how to go about implementing the corporate strategies as instructed by the headquarters. Expatriate spouses on the other hand are more exposed to making cultural gaffes due to the simple reason of them having to encounter more HCNs while running along with their daily activities.

The positive influence of $\mathrm{CQ}$ on the different facets of adjustment lends credit to anxiety/uncertainty management (AUM) theory (Gudykunst, 2005) which indicates that by being culturally intelligent, expatriate spouses could minimize the uncertainty and anxiety that stems from being in a culturally different environment. Consequently, they could expend more effort for social integration initiatives thus having positive expatriate performance outcomes. In addition, successful interaction and adjustment will in turn positively influence expatriates' contextual performance, which can be considered an important element that can spur task performance.

For spouses, adjustment to the host country is crucial because most often, they have to start anew with the quest of trying to integrate themselves with the local community. For them, due to their daily activities, they are more in direct contact with the locals. Thus being culturally aware of these differences would make them more receptive to the changes that they have to make in order to minimize cultural blunders. Although Malaysia is a modern country, cultural issues especially religious practices remain sensitive issues that the locals are less forgiving of (Tahir \& Ismail, 2007). CQ is an important antecedent to host country adjustment due to cultural aspects remains a sensitive issue to the locals. Making an effort to learn cultural-related behavior would be addressing the main concept established in Gudykunst's anxiety/uncertainty management (AUM) theory which allows for better management of the negative feelings associated with relocating to a new environment thus enhancing the effectiveness of intercultural communication in future encounters with the locals.

Additionally, due to the high number of expatriate families in Malaysia, expatriate related associations and societies are available for like-minded people. Therefore, spouses do not actually need to depend on their better halves for companionship. Having said that, although spouse adjustment was not proven to influence expatriate performance, indirectly, spouses do play a salient role in the expatriates' lives because they are still a family unit. Additionally, the main finding here is the relationship between spouse adjustment to expatriate performance goes in a sequential manner. The findings point to the impact of spouse general adjustment that could trigger spouse interaction adjustment, which in turn influences expatriate contextual performance and ultimately helps to improve expatriate task performance. Thus, in this manner, spouse adjustment does influence expatriate performance. 


\section{Conclusion}

Despite the exorbitant costs that are involved in hiring expatriates, the trend to continue deploying expatriates seem to be continuing into the future. This brings the impetus to ensure expatriation failures are minimized while simultaneously providing the platform where adjustments in the host country are better facilitated. This study tried to shift attention from technical, work related elements to a non-work setting with an emphasis on social support and cultural intelligence as the predicting factors of both expatriate and spouse adjustment and subsequent performance. The inclusion of the family members' adjustment would be an added testament indicating the strong influence of the family on the expatriate's work and non-work elements as proven by previous scholars (see Haslberger \& Brewster, 2008; Tung, 1981; Shaffer \& Harrison, 2001; Takeuchi, Yun \& Tesluk, 2002). This study is especially pertinent in a multiracial, multiethnic country like Malaysia.Where possible, with the influence that the organizations have in the host country, spouses should be referred to relevant organizations that could fully utilize the skills that the spouses have to offer on a freelance basis. This would help the spouses feel empowered and provide a sense of continuity from what they have been doing in the home country. This will also help to minimize feelings of 'resentment' that they might feel towards the expatriates as a result of an emotional upheaval that is associated with the stress of relocating to a new environment.

Despite the efforts to ensure this study is carried out meticulously, there are some limitations that might affect its contributions and generalizability. The most significant is the sample size which is relatively small compared to the number of constructs and proposed relationships. A larger sample would enable a more rigorous analysis using Structural Equation Modeling and there would be less concern on the strain of sample size-parameter. Secondly, this study is a cross-sectional study thus causality could not be inferred. The cross-sectional nature of the date used restricts conclusions to those of association and not causation. Hence, a more beneficial investigation of expatriate adjustment would be possible through a longitudinal study. The usage of self-rated performance in a cross-sectional study would increase the possibility of common method variance (CMV) where both the dependent and focal explanatory variables are perceptual measures derived from the same respondent (Podsakoff \& Organ, 1986). Therefore, future research should endeavor to minimize this. Finally, these findings can only be generalized to the countries that have similar cultural background i.e. South East Asian countries, as Malaysia. However, it is interesting to see whether the same model could be replicated to the Western environment.

In spite of such limitations, this study makes a number of important contributions that could help to improve the understanding of looking at expatriation from a non-technical and non-work perspective. Most essentially, it highlights the importance of acknowledging the support of stakeholders and cultural differences for a better comprehension of cultural-related situations which would lead to improved relationships among various entities and ultimately enhancing adjustment and performance in the host country. It also highlighted the pivotal role that the accompanying spouses or the 'significant others' play in facilitating the work and social relationships between the expatriates and the local co-workers and the local community.

\section{References}

Abdullah, A. (1992). The influence of ethnic values on managerial practices in Malaysia. Malaysian Management Review, 27, 3-18.

Abdullah, A. (1996). Going Global: Cultural Dimensions in Malaysian Management. Kuala Lumpur : Malaysian Institute of Management.

Albright, S., Chu, A., \& Austin, L. (1993). Moving and Living Abroad: A Complete Handbook for Families (ed.). New York: Hippocrane Books.

Anderson, J. C., \& Gerbing, D. W. (1984). The Effect of Sampling Error on Convergence, Improper Solutions, and Goodness-Of-Fit Indices for Maximum Likelihood Confirmatory Factor Analysis. Psychometrika, 49, 155-173. http://dx.doi.org/10.1007/BF02294170

Ang, S., Dyne, L., Koh, C., Ng, K. Y., Templer, K. J., Tay, C., \& Chandrasekar, N. A. (2007). Cultural intelligence: Its measurement and effects on cultural judgment and decision making, cultural adaptation and task performance. Management and Organisation Review, 3, 335-371. http://dx.doi.org/10.1111/j.1740-8784.2007.00082.x

Arbuckle, J. L. (2007). Amos 16.0 Users Guide. Chicago: SPSS Inc.

Bandura, A. (1977). Social Learning Theory. Prentice-Hall: New Jersey.

Bell, M. P., \& Harrison, D. A. (1996). Using intra-national diversity for international assignments: A model of bicultural life experiences and expatriate adjustment. Human Resources Management Review, 6, 47-74. http://dx.doi.org/10.1016/S1053-4822(96)90004-2 
Berger, C., \& Calabrese, R. (1975). Some explorations in initial interaction \& beyond: Toward a developmental theory of interpersonal communication. Human Communication Research, 1, 99-112. http://dx.doi.org/10.1111/j.1468-2958.1975.tb00258.x

Berry, J. W. (1997). Immigration, acculturation, and adaptation. Applied Psychology: An International Review, $46,5-68$.

Bhaskar-Shrinivas, P., Harrison, D. A., Shaffer, M. A., \& Luk, D. M. (2005). Input-based \& time-based models of international adjustment: Meta-analytic evidence and theoretical extensions. Academy of Management Journal, 48, 257-281. http://dx.doi.org/10.5465/AMJ.2005.16928400

Black, J. S. (1988). Work role transitions: A study of American expatriate managers in Japan. Journal of International Business Studies, 1992, 277-294. http://dx.doi.org/10.1057/palgrave.jibs.8490383

Black, J. S., \& Gregersen, H. B. (1991). Antecedents to cross-cultural adjustment for expatriates in Pacific Rim assignments. Human Relations, 44, 497-515. http://dx.doi.org/10.1177/001872679104400505

Black, J. S., \& Gregersen, H. B. (2000). High impact training: Forging leaders for the global frontier. Human Resource http://dx.doi.org/10.1002/1099-050X(200022/23)39:2/3<173::AID-HRM7>3.0.CO;2-W

Black, J. S., \& Mendenhall, M. (1990). Cross-cultural effectiveness: A review and a theoretical framework for future research. Academy of Management Review, 15, 113-136.

Black, J. S., \& Stephens, G. K. (1989). The influence of the spouse on American expatriate adjustment and intent to stay in Pacific Rim overseas assignments. Journal of Management, 15, 529-544. http://dx.doi.org/10.1177/014920638901500403

Black, J. S., Gregersen, H. B., \& Mendenhall, M. E. (1992). Global Assignments. San Francisco: Jossey-Bass Publishers.

Black, J. S., Mendenhall, M., \& Oddou, G. (1991). Toward a comprehensive model of international assignment: An integration of multiple theoretical perspectives. Academy of Management Review, 16, 291-317.

Borman, W. C., \& Motowidlo, S. J. (1997). A Theory of Individual Differences in Task and Contextual Performance. Human Performance, 10, 71-83. http://dx.doi.org/10.1207/s15327043hup1002_1

Brislin, R., Worthley, R., \& Macnab, B. (2006). Cultural Intelligence: Understanding behaviors that serve people's goals. Group and Organizational Management, 31, 40-55. http://dx.doi.org/10.1177/1059601105275262

Caligiuri, P. M. (1997). Assessing expatriate success: Beyond just "being there." In Z. Aycan (Ed.), New approaches to employee management, Vol. 4 - Expatriate management: Theory and research. Greenwich: CT JAI Press.

Caligiuri, P. M. (2000). The big five personality characteristics as predictors of expatriates desire to terminate the assignment and supervisor-rated performance. Personnel Psychology, 53, 67-88. http://dx.doi.org/10.1111/j.1744-6570.2000.tb00194.x

Campbell, J. P. (1990). Modeling the performance prediction problem in industrial and organizational psychology. In M. D. Dunnette \& L. M. Hough (Eds.), Handbook of Industrial and Organizational Psychology. Palo Alto, CA: Consulting Psychologists Press.

Dillman, D. A. (2007). Mail and Internet Surveys - The Tailored Design Method. New Jersey: John Wiley \& Sons.

Dyne, L. (2005). 20-Item Measure of Cultural Intelligence (CQ). Michigan: Cultural Intelligence Center.

Earley, P. C., \& Ang, S. (2003). Cultural Intelligence: Individual Interactions across Cultures. Palo Alto: Stanford University Press.

Flynn, G. (1995). Expatriate success is no longer just a question of job skills. Personnel Journal, 74, 29-34.

Furnham, A., \& Bochner, S. (1986). Culture Shock: Psychological Reactions to Unfamiliar Environments. London: Methuen And Co.

Gudykunst, W. B. (1988). Uncertainty \& Anxiety. In Y. Y. Kim \& W. B. Gudykunst (Eds.), Theories in Intercultural Communication. Newbury Park, CA: Sage.

Gudykunst, W. B. (1998). Applying anxiety/uncertainty management (AUM) theory to intercultural adaptation training. International Journal of Intercultural Relations, 22, 227-250. http://dx.doi.org/10.1016/S0147-1767(98)00005-4

Gudykunst, W. B. (2005). An anxiety/uncertainty management (AUM) theory of strangers' intercultural adjustment. Theorising about Intercultural Communication. Thousand Oaks, CA: Sage. 
Haslberger, A., \& Brewster, C. (2008). The expatriate family: an international perspective. Journal of Managerial Psychology, 23, 324-346. http://dx.doi.org/10.1108/02683940810861400

Hechanova, R., Beehr, T. A., \& Christiansen, N. D. (2003). Antecedents and consequences of employees' adjustment to overseas assignments: a meta-analytic review. Applied Psychology: An International Review, 52, 213-236. http://dx.doi.org/10.1111/1464-0597.00132

Hemmasi, M., Downes, M., \& Varner, I. (2010). An empirically driven multidimensional measure of expatriate success: Reconciling the discord. International Journal of Human Resource Management, 21, 982-998. http://dx.doi.org/10.1080/09585191003783447

James, L. R., Mulaik, S. A., \& Brett, J. M. (1982). Causal Analysis: Assumptions, Model and Data. Beverly Hills: Sage.

Javidan, M., \& House, R. J. (2002). Cultural Acumen for the Global Manager: Lessons from Project GLOBE. Organizational Dynamics, 29, 289-305. http://dx.doi.org/10.1016/S0090-2616(01)00034-1

Kraimer, M. L., \& Wayne, S. J. (2004). An examination of perceived organizational support as a multidimensional construct in the context of an expatriate assignment. Journal of Management, 30, 209-237. http://dx.doi.org/10.1016/j.jm.2003.01.001

Kraimer, M. L., Wayne, S. J., \& Jaworski, R. A. (2001). Sources of support and expatriate performance: The mediating role of expatriate adjustment. Personnel Psychology, 541, 71-99. http://dx.doi.org/10.1111/j.1744-6570.2001.tb00086.x

Kupka, B., \& Cathro, V. (2007). Desperate housewives - social \& professional isolation of German expatriated spouses. The International Journal of Human Resource Management, 18, 951-968. http://dx.doi.org/10.1080/09585190701320908

Lim, L. (2001). Work-related values of Malays and Chinese Malaysians. International Journal of Cross Cultural Management, 19, 209-226. http://dx.doi.org/10.1177/147059580112005

Lin, N., Cook, K. S., \& Burt, R. S. (2001). Social Capital: Theory and Research. New Jersey: Aldine Transaction.

Loehlin, J. C. (2004). Latent Variable Models: An Introduction to Factor, Path and Structural Equation Analysis. London: Lawrence Erlbaum Associates Inc.

Malek, M. A., \& Budhwar, P. (2011). Sources of support and expatriation - A multiple stakeholder perspective of expatriate adjustment and performance in Malaysia. EIASM Workshop. Moscow.

Mavondo, F. T., \& Rodrigo, E. M. (2001). The Effect of Relationship Dimensions on Interpersonal and Interorganizational Commitment in Organizations Conducting Business between Australia and China. Journal of Business Research, 52, 111-121. http://dx.doi.org/10.1016/S0148-2963(99)00064-8

Mendenhall, M., \& Oddou, G. (1985). The Dimensions of Expatriate Acculturation: A Review. Academy of Management Review, 10, 39-47.

Neupert, K. E., Baughn, C. C., \& Dao, T. T. L. (2005). International management skills for success in Asia - A need-based determination of skills for foreign managers and local managers. Journal of European Industrial Training, 29, 165-180. http://dx.doi.org/10.1108/03090590510585118

Nicholson, N., \& Imaizumi, A. (1993). The adjustment of Japanese expatriates living and working in Britain. British Journal of Management, 4, 119-153. http://dx.doi.org/10.1111/j.1467-8551.1993.tb00052.x

Peterson, B. (2004). Cultural Intelligence: A Guide to Working with People from Other Cultures. Boston, MA: Intercultural Press.

Podsakoff, P. M., \& Organ, D. W. (1986). Self-reports in organizational research: Problems and prospects. Journal of Management, 12, 531-544. http://dx.doi.org/10.1177/014920638601200408

Podsakoff, P. M., Mackenzie, S. B., Paine, J. B., \& Cachrach, D. G. (2000). Organizational Citizenship Behaviors: A Critical Review of the Theoretical and Empirical Literature and Suggestions for Future Research. Journal of Management, 26, 513-563. http://dx.doi.org/10.1177/014920630002600307

Pomeroy, A. (2006). Better executive on boarding processes needed. HR Magazine, 51(8), 16.

Punnett, B. J. (1997). Towards Effective Management of Expatriate Spouses. Journal of World Business, 32, 243-257. http://dx.doi.org/10.1016/S1090-9516(97)90010-9

Schermerhorn, J. R. J., \& Bond, M. H. (1997). Cross-Cultural Leadership Dynamics in Collectivism and High Power Distance. Leadership and Organization Development Journal, 18, 187-193. http://dx.doi.org/10.1108/01437739710182287

Schwab, D. P. (2005). Research Methods for Organizational Studies. London: Lawrence Erlbaum Associates. 
Selmer, J. (1998). Expatriation: Corporate Policy, Personal Intentions and International Adjustment. The International Journal of Human Resource Management, 9, 996-1007. http://dx.doi.org/10.1080/095851998340711

Shaffer, M. A., \& Harrison, D. A. (1998). Expatriates psychological withdrawal from international assignments: work, nonwork, and family influences. Personnel Psychology, 51, 87-118. http://dx.doi.org/10.1111/j.1744-6570.1998.tb00717.x

Shaffer, M. A., \& Harrison, D. A. (2001). Forgotten partners of international assignments. Development and test of a model of spouse adjustment. Journal of Applied Psychology, 86, 238-254. http://dx.doi.org/10.1037/0021-9010.86.2.238

Shay, J. P., \& Baack, S. (2006). An empirical investigation of the relationships between modes and degree of expatriate adjustment and multiple measures of performance. International Journal of Cross Cultural Management, 6, 275-294. http://dx.doi.org/10.1177/1470595806070634

Shin, S. J., Morgeson, F. P., \& Campion, M. A. (2007). What You Do Depends on Where You Are: Understanding How Domestic and Expatriate Work Requirements Depend Upon the Cultural Context. Journal of International Business Studies, 38, 64-83. http://dx.doi.org/10.1057/palgrave.jibs.8400247

Singh, J., \& Wilkes, R. E. (1996). When Consumers Complain: A Path Analysis of the Key Antecedents of Consumer Complaint Response Estimates. Journal of the Academy of Marketing Science, 24, 350-365. http://dx.doi.org/10.1177/0092070396244006

Tahir, A. H. M., \& Ismail, M. (2007). Cross-Cultural Challenges and Adjustments of Expatriates: A Case Study in Malaysia. Turkish Journal of International Relations, 6, 72-99.

Tajfel, H. (1982). Instrumentality, Identity and Social Comparisons. In H. Tajfel (Ed.), Social Identity and Intergroup Relations. Cambridge: Cambridge University Press.

Tajfel, H., \& Turner, J. C. (1985). The Social Identity Theory of Intergroup Behaviour. In S. Worchel \& W. G. Austin (Eds.), Psychology of Intergroup Relations. Chicago: Nelson-Hall.

Takeuchi, R. (2010). A critical review of expatriate adjustment research through a multiple stakeholder view: Progress, emerging trends and prospects. Journal of Management, 36, 1-25. http://dx.doi.org/10.1177/0149206309349308

Takeuchi, R., Wang, M., Marinova, S. V., \& Yao, X. (2009). The role of domain-specific perceived organizational support during expatriation and their implications for performance. Organization Science, 20, 621-634. http://dx.doi.org/10.1287/orsc. 1080.0403

Takeuchi, R., Yun, S., \& Tesluk, P. E. (2002). An examination of crossover and spillover effects of spousal and expatriate cross-cultural adjustment on expatriate outcomes. Journal of Applied Psychology, 874, 655-666. http://dx.doi.org/10.1037/0021-9010.87.4.655

Toh, S. M., \& DeNisi, A. S. (2005). A local perspective to expatriate success. Academy of Management Executive, 19, 132-146.

Tucker, M. F., Bonial, R., \& Lahti, K. (2004). The definition, measurement and prediction of intercultural adjustment and job performance among corporate expatriates. International Journal of Intercultural Relations, 283, 221-251. http://dx.doi.org/10.1016/j.ijintrel.2004.06.004

Tung, R. L. (1981). Selection and Training of Personnel for Overseas Assignments. Columbia Journal of World Business, 16, 21-25.

Tung, R. L. (1987). Expatriate assignments: Enhancing success and minimizing failure. Academy of Management Executive, 1, 117-126. http://dx.doi.org/10.5465/AME.1987.4275826

Wang, M., \& Takeuchi, R. (2007). The role of goal orientation during expatriation: A cross-sectional and longitudinal investigation. Journal of Applied Psychology, 92, 1437-1445. http://dx.doi.org/10.1037/0021-9010.92.5.1437

Wang, X. (2001). Expatriate social network, psychological well-being and performance - A theoretical examination and an empirical test. Unpublished Doctoral Dissertation, McGill University.

\section{Copyrights}

Copyright for this article is retained by the author(s), with first publication rights granted to the journal.

This is an open-access article distributed under the terms and conditions of the Creative Commons Attribution license (http://creativecommons.org/licenses/by/3.0/). 